\title{
EL POSITIVISMO EN SERIO ¿ES POSIBLE HABLAR DE PRINCIPIOS EN EL POSITIVISMO JURÍDICO?'
}

\author{
Positivism Seriously: is it Possible to Speak of \\ Principles in Legal Positivism?'
}

Juan Gabriel Acosta Castro*

Fecha de Recepción: Noviembre 3 de 2014

Fecha de Aceptación: Noviembre 10 de 2014

SUMARIO: 1. Introducción; 2.El concepto del derecho; 3. Los derechos en serio; 4. El positivismo jurídico en serio. Es posible hablar de principios en el positivismo jurídico.

5. Referencias bibliográficas.

\footnotetext{
${ }^{1}$ El presente trabajo es un avance de investigación al interior del grupo de investigación Demosophia de la facultad de derecho de la universidad de San Buenaventura Cartagena, bajo el proyecto de investigación titulado: Transformaciones de la teoría del derecho a partir de los desarrollos del Neoconstitucionalismo, inscrito en la línea, sistemas jurídicos y problemas sociales. Fecha de inicio: 3 de febrero-2014. Fecha de finalización: 20 de agosto-2014.

- Abogado Universidad de Cartagena. Maestrante en Derecho Universidad de Medellín. Docente de tiempo completo facultad de derecho Universidad de San Buenaventura.jacosta@usbctg.edu.co
} 


\section{COMO SE CITA ESTE ARTÍCULO (APA 6)}

Acosta Castro, J. G. (2015) El positivismo en serio ¿es posible hablar de principios en el positivismo jurídico? (Y. Carrillo De la rosa, Ed.) Revista Jurídica Mario Alario D'Filippo, VII (13), pág. 80-90

\section{RESUMEN}

En este artículo se intenta mostrar cómo puede justificarse la existencia de principios, a partir de la teoría positivista del Derecho, a pesar de que su incursión en la teoría contemporánea se muestre como novedosa. Se hará especial referencia al debate entre Hart y Dworkin, y las consecuencias que de éste se derivan.

\section{PALABRAS CLAVE}

Principios jurídicos, positivismo jurídico, teoría del derecho.

\section{ABSTRACT}

This article attempts to show how you can justify the existence of principles from the positivist theory of law, even though its foray into contemporary theory is shown as new. Particular reference to the debate between Hart and Dworkin, and the consequences of this will arise.

\section{KEY WORDS}

Legal principles, legal positivism, legal theory 


\section{INTRODUCCIÓN}

Bajo un título bastante sugestivo en el año de 2007, los profesores Manuel Atienza y Juan Luis Manero, de la Universidad de Alicante, realizaron una propuesta muy llamativa. En el artículo Dejemos atrás el positivismo jurídico (2007), sostienen, que el positivismo jurídico en cualquiera de sus variantes ${ }^{2}$, resulta hoy insuficiente para explicar los desarrollos de la Teoría del Derecho en el Estado Constitucional, al menos por dos razones: es irrelevante por una parte, y por otra se constituye en un obstáculo para el adecuado estudio de la Teoría del Derecho actualmente. En primer lugar, los presupuestos mínimos de los que parten los autores positivistas ${ }^{3}$, son un lugar común aún para autores no positivistas ${ }^{4}$, por lo que concluyen que "[el positivismo jurídico] no puede constituir ya hoy una de las señas de identidad de una teoría o de una concepción del Derecho, porque todas las que tienen algún grado de vigencia la comparten" (Atienza, Manero $2007,21)$. Y en segundo lugar, el carácter descriptivo del que parten las propuestas teóricas positivistas "lo inhabilitan para intervenir competentemente en algunas discusiones hoy centrales" (Atienza, Manero. 2007,24). Lo anterior, adquiere mayor sentido, si se tiene presente el pretendido carácter neutral y libre de valoraciones con que se aborda el estudio del Derecho desde el positivismo jurídico, lo cual, no le permitiría tener las herramientas suficientes para entrar a discutir problemas como: los conflictos entre principios jurídicos y entre derechos constitucionales. Las consideración precedentes, le permiten a nuestros autores señalar finalmente que "el positivismo jurídico ha agotado ya, nos parece, su ciclo histórico". (Atienza, Manero. 2007,25)

A lo expuesto por los profesores españoles en el segundo punto, a título de ejemplo, podría agregarse una situación adicional: la forma en que las distintas jurisdicciones constitucionales han venido asumiendo la defensa de los derechos fundamentales; y en consecuencia, el uso cada vez más frecuente de un lenguaje menos neutral y más comprometido con la defensa de ciertos valores y principios constitucionales ${ }^{5}$, ha limitado el poder persuasivo y explicativo que la teoría descriptiva o positivista del derecho, pudo haber tenido en el pasado.

Parecería por todo lo anterior; y especialmente en esto último, el mayor interés por temas relacionados con los principios y valores, en donde radicaría la deficiencia más notoria del positivismo jurídico, por lo que deberíamos adherirnos a teorías no positivistas para el estudio del Derecho, pues parece, que pueden dar mejores explicaciones para la comprensión de los cambios que ha sufrido el Derecho desde la segunda mitad del siglo XX ${ }^{6}$.

\footnotetext{
${ }^{2}$ Los autores enuncian los principales focos de discusión actual del positivismo jurídico: incluyente, excluyente y axiológico. Aunque también, son claros en especificar, que bajo un mismo rótulo se agrupa una variante finita de autores con propuestas teóricas diferentes; Kelsen, Hart, Raz, Bobbio, Carió, Ross entre otros

${ }^{3}$ Se hace referencia a la tesis de las fuentes sociales, tesis de la separación conceptual entre derecho y moral.

${ }^{4}$ “Ni Radbruch, ni Fuller, ni (para poner ejemplos más recientes de posturas iusnaturalistas) Finnis tendrían en realidad nada que objetar frente a esa tesis [de las fuentes sociales del Derecho] no es una tesis discutida seriamente por nadie (...) en relación con la segunda tesis, la de la separación entre el Derecho y la moral, si la limitamos a aquello que comparten todos los que se denominan positivistas, es una tesis tan mínima que tampoco constituye, desde luego, una posición distintiva en la teoría del Derecho: también la mayor parte de quienes se autodenominan iusnaturalistas estarían de acuerdo con esta". (Atienza, Manero. 2007. 21)

${ }^{5}$ Para el caso colombiano, es bastante llamativo lo expuesto por la Corte Constitucional en la Sentencia T 406 de 1992, al pronunciarse sobre la tutela efectiva de los derechos a la vida en condiciones dignas y a la salubridad pública, ante la falta de terminación de una obra de alcantarillado público.

${ }^{6}$ Una lectura sobre los cambios de la teoría del derecho en el estado constitucional GARCíA FIGUEROA, A. "La teoría del derecho en tiempos del constitucionalismo". En Neoconstitucionalismo(s). Editorial Trotta. Madrid. 2003.
} 
Pero tal intensión, no es la que se defenderá en este escrito. Por el contrario, la línea argumentativa que lo atraviesa se dirige en un sentido completamente contrario. Se intentará mostrar cómo la teoría positivista del Derecho sí es capaz de hacer frente a los cambios ocurridos, y en particular, a los principios jurídicos, considerando además, que se convierte en una herramienta útil y básica para la promoción de cambios, y además, puede servir de base para formulación de críticas a los modelos jurídicos imperantes ${ }^{7}$.

No obstante, tal como lo anotaron los profesores Atienza y Manero, el positivismo jurídico tiene muchas variantes, por lo que nos limitaremos al estudio de la propuesta realizada por H.L.A. HART, una de las más influyentes en el último siglo. Pero no podríamos abordarla adecuadamente, sin hacer mención a las críticas realizadas por R. DWORKIN y que posibilitaron una respuesta a aspectos que no fueron considerados inicialmente por HART en su teoría, esto es, los principios. A partir de esto, y teniendo en cuenta aspectos generales de la Teoría General del Derecho, podremos argumentar que si se toma el positivismo jurídico en serio, los llamados principios sí son compatibles con sus principales propuestas teóricas y en consecuencia, se encuentra plenamente habilitado para dar razón de ellos.

Para logro de los fines anteriores, inicialmente se hará un estudio de la propuesta teórica de Hart, en segundo lugar, se expondrán las críticas realizadas por Dworkin y finalmente la respuesta que da el profesor de Oxford a estas objeciones y el porqué la pertinencia y utilidad de la teoría positivista para el estudio del Derecho en el Estado constitucional.

\section{EL CONCEPTO DEL DERECHO}

En el libro The Concept of Law, que vio a la luz en lengua inglesa por primera vez en 1961, la intensión de Hart es clara: hacerle frente a una pregunta persistente ${ }^{8}$, de larga duración en la historia de la teoría jurídica ¿Qué es el Derecho?

El proponer esto, no busca en sentido alguno dar una definición única de qué es Derecho, sino más bien describir la estructura característica de los sistemas jurídicos contemporáneos y con ello, identificar lo que se entiende por derecho.

Desde esta perspectiva, el primer paso en el trabajo de HART es mostrar cómo la teoría imperativa del derecho formulada por AUSTIN, resulta insuficiente para explicar el Derecho en la sociedades contemporáneas $^{9}$. Una vez hecho lo anterior y ante la necesidad de comprender satisfactoriamente que debería entenderse por derecho, HART propone su visión particular sobre el tema: el Derecho son reglas. A partir de este distanciamiento, con la teoría imperativa y el hábito de obediencia, se identifica en los sistemas jurídicos la existencia de dos tipos de reglas: las reglas primarias y secundarias. Al respecto sostiene que "mientras las reglas primarias se ocupan de las

\footnotetext{
${ }^{7}$ Debemos aceptar, que este primer intento por abordar los desafíos del positivismo jurídico en el Estado constitucional, no pretende ser un trabajo acabado, por el contrario, somos conscientes que estas líneas constituyen una aproximación temeraria que necesita ser refinadas.

${ }^{8}$ HART, H.L.A. “El concepto del derecho". Abeledo-perrot. Buenos Aires. 1963. Cáp. 1.

${ }^{9}$ A este propósito HART dedica los tres primeros capítulos de su obra.
} 
acciones que los individuos deben o no hacer, estas reglas secundarias se ocupan de las reglas primarias. Ellas identifican la manera en que las normas reglas primarias pueden ser verificadas en forma concluyente, introducidas, eliminadas, modificadas, y su violación determinada de manera incontrovertible". (Hart. 1963, 117)

Esta última clase de reglas, se subdivide en tres clases: reglas de cambio, regla de adjudicación y regla de reconocimiento. Las primeras, permiten conocer cómo se crean, modifican o eliminan las reglas primarias; las segundas, permiten dirimir un conflicto entre las reglas primarias o aplicar sanciones cuando se han dejado de aplicar (Hart. 1963, pp. 118-120) y la tercera, se convierte en el punto arquimédico de la teoría de HART, por cuanto "ella establece el criterio que permite reconocer las reglas primarias de forma incontrovertible como derecho válido al señalar las características que debe tener una norma jurídica para que pueda ser identificada como perteneciente al sistema jurídico". (Carrillo. 2008, 113)

La regla de reconocimiento entonces, pasa a ser la norma validante de las demás normas, al decir ella misma cuáles son las condiciones que deben satisfacer para que las demás normas, se consideren Derecho.

Describe, que en toda sociedad el sistema jurídico se encuentra conformado en forma piramidal, es decir jerárquica, y que el reconocimiento o pertenencia de una norma a tal sistema, estriba en que se derive válidamente de una norma superior. Pero, cuando se llega a la norma última del sistema, la constitución por ejemplo, ¿cómo se hace para aceptar y derivar su validez, si no hay norma que a su vez la valide?

Esta encrucijada de remisión al infinito, es resuelta por HART apelando no a un criterio presupuesto $^{10}$, sino a uno que puede ser verificado mediante una práctica social. La regla de reconocimiento está dada por una práctica social compleja que se encuentra en sintonía con las actuaciones de los operadores judiciales, es decir, se acepta. En palabras de HART:

"[L]a afirmación de que ella existe solo puede ser un enunciado de hecho externo. Porque mientras que una regla subordinada de un sistema puede ser válida, y en ese sentido 'existir' aun cuando sea generalmente desobedecida, la regla de reconocimiento solo existe como una práctica compleja, pero normalmente concordante de los tribunales, funcionarios y particulares, al identificar al derecho por referencia a ciertos criterios. Su existencia es una cuestión de hecho". $(1963,137)$

En esta forma, HART evita incurrir en la falacia naturalista, consistente en derivar un ser-el derechode un deber ser -la moral- al no apelar a un concepto subjetivo y metafísico, sino a uno concreto, social y jurídico. En la base de lo anterior, se encuentra un argumento: cuando hablamos de la regla de reconocimiento se pasa de un enunciado de validez jurídica, a un enunciado de valor ${ }^{11}$.

\footnotetext{
${ }^{10}$ Como en su ocasión formulara H. Kelsen y que daría al traste con su teoría del derecho. Una buena explicación en este punto y la falencia de la norma fundamental en Kelsen. (NINO.2003)

${ }^{11}$ Añade Hart: "cuando después de decir que una norma particular es válida porque satisface la regla (...) sostenemos que esta última regla es usada (...) por los funcionarios y particulares como regla de reconocimiento última, hemos pasado de un enunciado que afirma la validez de una regla del sistema a una enunciado externo de hecho, que un observador podría hacer aunque no aceptara el sistema". Ibídem. (134).
} 
Hasta aquí, los puntos que creemos esenciales para comprender la teoría positivista propuesta por HART y aquellos que nos permitirán abordar los planteamientos expuestos por R. DWORKIN ${ }^{12}$.

\section{LOS DERECHOS EN SERIO}

En Taking rights seriusly el propósito de R. DWORKIN consistió en hacerle frente a la teoría liberal dominante en sus dos flancos principales: qué es el Derecho y cómo debe ser el Derecho y las instituciones legales. La primera reflejada en la teoría positivista formulada por HART y la segunda inspirada en la teoría utilitarista formulada por BENTHAM (Carrillo. 2008, pp.121-122). Centraremos nuestra atención sobre el primer punto.

R. DWORKIN parte del supuesto que la teoría positivista se condensaba en tres puntos: a) El Derecho es un conjunto de normas especiales identificables de otras por su origen o pedigree y no su contenido; esto es posible, mediante el uso de una regla de reconocimiento, b) el Derecho se agota en estas normas válidas y cuando no hay ninguna norma aplicable a un caso, el juez ejerce su discreción, y c) alguien tiene una obligación, si una norma jurídica exige hacer algo o lo prohíbe. (Dworkin. 1989, pp. 65-66)

Este esqueleto del positivismo jurídico está presente en AUSTIN, pero al igual que HART, señala que es muy simple y por ello señala el mejor grado de elaboración y complejidad de la propuesta hartiana (Dworkin. 1989, 68). A pesar de lo anterior, dicha teoría no es capaz de dar cuenta por la existencia de ciertas normas que son utilizadas por los tribunales para resolver determinados casos, casos difíciles, cuando no existe una norma aplicable directamente: los principios.

Un principio es un "estándar que ha de ser observado, no porque favorezca o asegure una situación económica, política o social que se considere deseable, sino porque es una exigencia de justicia, la equidad o alguna otra dimensión de la moralidad" (Dworkin. 1989, 72). Como ejemplo de ello, cita dos casos: Riggs Vs Palmer ${ }^{13}$ y Henningsen Vs Bloomfield motors, inc.

En el primero de ellos, se deber resolver sobre la entrega de la herencia al nieto que aparecía en el testamento, pero que para obtenerla había asesinado a su abuelo; y en el segundo, el caso se centra en establecer la responsabilidad de un fabricante de autos por la venta de productos defectuosos. En ambas situaciones, los tribunales no apelan a las reglas de derecho o leyes promulgadas para resolver el caso, sino a principios: nadie puede beneficiarse de su propia culpa, para el primero; y

\footnotetext{
${ }^{12}$ En una conferencia pronunciada en la Universidad Autónoma de Madrid en 1979 y que posteriormente fue publicada, HART propone lo que se conoce como las tres tesis del positivismo jurídico: la tesis de las fuentes sociales, la tesis de la discrecionalidad y la de la separación. La tesis de las fuentes sociales implica que para que "el derecho exista debe haber alguna forma de práctica social que incluya a los jueces y a los ciudadanos ordinarios, y esta práctica social determina lo que en cualquier sistema jurídico dado son las fuentes últimas del derecho o criterios últimos o tests, últimos de validez jurídica"; la tesis de la discrecionalidad está asociada con la existencia de "ciertos casos no previstos y no regulados legalmente, es decir, casos para los que ningún tipo de decisión es dictado por el derecho claramente establecido y, en consecuencia, el derecho es parcialmente indeterminado o incompleto" estando los jueces facultados para crear derecho en tales circunstancias y la tesis de la separación que se refiere a la no vinculación necesaria entre Derecho y Moral (Hart. 1980) . Contra todas ellas a partir de la concepción interpretativa que tiene Dworkin sobre el derecho formulara sus críticas. No nos detendremos en ellas por exceder al objetivo de nuestro trabajo.

${ }^{13}$ La traducción al castellano: de este caso puede consultarse Jiménez, Fabra \& Guzmán. 2001-2008.
} 
entre otros, no se puede aplicar un pacto en el que una de las partes se ha aprovechado injustamente de las necesidades económicas de la otra (Dworkin. 1989, 74), en el segundo.

Si bien tanto las normas jurídicas y los principios se dirigen a decisiones particulares, como lo señala DWORKIN, se diferencia en el carácter de la orientación que cada una proporciona. Las normas se aplican de forma disyuntiva, "de todo o nada, esto es, si se dan determinados hechos que caen dentro de la órbita determinada regla estipulada como válida, entonces se actualiza la respuesta que establece la regla" (Carrillo. 2008, 124). Entre tanto, un principio no establecen consecuencias jurídicas en forma tan precisas por su no cumplimiento, "más bien enuncia una razón que discurre en un sola dirección" y que en tales situaciones, "los funcionarios deben tenerlo en cuenta, si viene al caso, como criterio que les determine a inclinarse en uno u otro sentido" (Dworkin. 1989, 76). Desde esta perspectiva, los principios no responden a una lógica disyuntiva, sino a una dimensión de peso o importancia. (Dworkin. 1989, 78)

Haciendo un contraste con las características que resalta DWORKIN sobre el positivismo, tendríamos que las mismas son fuertemente cuestionadas debido a que: a) no solo hacen parte del derecho normas que respondan a un pedigree, b) el derecho es más que normas, también se encuentra integrado por principios, y c) existen obligaciones jurídicas por fuera de las normas y contenidas en los principios.

Así, forzosamente tendríamos que sostener que al responder los principios a un criterio de moralidad, a una dimensión de peso, ser discutibles, incontables, y variantes, además, que deben ser tenidos en cuenta por los jueces al adoptar sus decisiones, el dogma de los positivistas de una regla maestra mediante la cual se identifica el derecho de una comunidad de otros estándares sociales, no existe.

Al fracturarse el punto arquimédico de la propuesta teórica sostenida por HART, esto es, la regla de reconocimiento sobre la cual erige su visión del derecho, las demás pretensiones también deben caer: el juez no es discrecional para tomar decisiones en casos difíciles, debe aplicar los principios, y al estar presente los mismos en el derecho, el lenguaje utilizado no es neutro, por el contrario valorativo y en consecuencia, no hay una pretendida separación entre derecho y moral ${ }^{14}$.

\section{EL POSITIVISMO JURÍDICO EN SERIO. ES POSIBLE HABLAR DE PRINCIPIOS EN EL POSITIVISMO JURÍDICO}

Cuando DWORKIN habló de tomarnos los derechos en serio lo hizo asumiendo que la teoría imperante no lo hacía, debido a que era incapaz de brindar una explicación adecuada de los sistemas jurídicos: no daba cuenta de los principios. (Fabra. 2008)

Pero tal ecuación, amerita ser replanteada. La razón, es que la lectura realizada por el profesor DWORKIN de la propuesta de HART, es parcial y adiciona elementos que no habían sido la intensión de

${ }^{14}$ La teoría que formulara inicialmente R. Dworkin es reformulada y adicionada en su obra posterior "El imperio de la justicia" (Law's Empire). 
este último autor. Así las cosas, al tomar el positivismo jurídico en serio, nos damos cuenta que sí es posible hablar de principios al interior de esta teoría y qué sus principales elementos, con algunas adiciones, si son capaces de brindar herramientas necesarias para el estudio del derecho en el Estado constitucional.

En el Post scriptum al Concepto del Derecho, HART sistematiza y responde a las críticas realizadas por DWORKIN a su teoría. Nos centraremos en la respuesta que brinda al tema de los principios. Al margen de mostrar cómo su teoría era de carácter general y descriptivo, muy por el contrario a la planteada por su adversario, particular y prescriptiva -por lo que ambas teorías se mueven en órdenes discursivos muy diferentes- sostiene, que no obstante no haber realizado un tratamiento sistemático de los principios en sus ideas originales, este hecho por sí solo, no invalida sus planteamientos y "lo que tenga de válido esta crítica puede ajustarse sin que esto conlleve graves consecuencias" para la teoría en su conjunto, algo "que podría subsanarse incluyendo principios junto con las reglas jurídicas como componentes de un sistema", sin "abandonar o modificar esencialmente ninguno de los temas Principales Del Libro". (Hart. 2000, 38)

Lo Primero que señala HART Es la Falsa Creencia de la que parte DWORKIN al considerar que el derecho solo está constituido por reglas aplicables en la forma de todo o nada (Hart. 2000, 37) y a partir de esto, formular una diferenciación tajante entre los principios y las reglas, confinando los primeros al ámbito de la validez o linaje y los segundos, a la dimensión del peso o importancia.

Los rasgos distintivos en los principios son: su amplitud, deseabilidad y que no son concluyentes, es decir, no imponen una decisión, sino que "señalan hacia, o cuentan a favor de, una [resolución]" (Hart. 2000, 37). Pero estas distinciones, conducen a que HART no vea en la pretendida diferenciación más que una cuestión de grado. Señala que dos normas pueden entrar en conflicto, pero que una de ellas se aplique en vez de otra, no supone su invalidez, solo que por su importancia es aplicable al caso en específico; además añade, que la argumentación de DWORKIN no es coherente, debido a que los conflictos no son exclusivamente entre reglas o exclusivamente entre principios, sino que también pueden existir entre reglas y principios, y cuando se resuelve a favor de los últimos, se pierde el carácter de todo o nada atribuido a las reglas ${ }^{15}$.

Por otra parte, conciliar la existencia entre la regla de reconocimiento y la existencia de los principios, no resulta problemática; aún más, se podría sostener una cierta similitud entre las propuestas de HART Y DWORKIN. A favor de esto, se argumenta que los principios no solo deben su valor al contenido, sino también a su linaje y en la medida en que son invocados, identificados, aplicados y aceptados por las autoridades judiciales, estos se relacionan con la regla de reconocimiento. Sostiene HART:

\footnotetext{
15 “Entre los casos que cita incluye el de Riggs Vs Palmer, en el cual el principio de que a nadie le está permitido beneficiarse de su propio dolo fue sostenido, no obstante el lenguaje claro de reglas legisladas que gobiernan los efectos del testamento, para impedir a un homicida heredar en virtud del testamento de su víctima. Este es un ejemplo de un principio que vence a una regla en conflicto, pero la existencia de este conflicto ciertamente muestra que las reglas no tienen el carácter de todo o nada, toda vez que son susceptibles de entrar en conflicto con los principios, los cuales pueden vencerlas". (Hart. 2000, pp. 41-42)
} 
"las reglas y las prácticas jurídicas, las cuales constituyen el punto de partida de una tarea interpretativa para identificar los principios (...) parece respaldar la idea de que para su identificación es necesario algo muy parecido a la regla de reconocimiento que identifique las fuentes de autoridad del derecho (...) la principal diferencia entre mi tesis y la de Dworkin aquí es que mientras yo atribuyo adscribo el acuerdo general que se da entre los jueces como criterio para la identificación de las fuentes del derecho a su aceptación compartida de reglas que prevén tal criterio, Dworkin prefiere hablar de "consensos", "paradigmas" y "presuposiciones" que comparten por los miembros de la misma comunidad interpretativa".(2000, 47)

En síntesis, en la medida en que los principios se aceptan en virtud de una práctica judicial, se identifican con la regla de reconocimiento; de modo que en adelante el conflicto no va versar más sobre la existencia de los principios, sino, sobre el papel de la moral en el derecho. (Fabra. 2008, 7) Hasta aquí, lo dicho muestra que sí es posible hablar de principios en el positivismo jurídico, al menos, en su corriente hartiana como se explicó. Pero adicional a ello, debemos agregar dos situaciones: el tema de los principios jurídicos no es de reciente creación, pero sí, de un renovado estudio y que el carácter descriptivo de la teoría positivista hace reforzar su importancia.

Frente al primer punto, basta con recordar que ante la fractura del dogma de la plenitud ${ }^{16}$ del ordenamiento jurídico, por la existencia de lagunas en la ley ${ }^{17}$, una de las formas en que se daba solución a ese vacío era mediante la aplicación de los principios generales del derecho ${ }^{18}$. En la actualidad, "Ios principios son uno de los ejes fundamentales de la filosofía, teoría y dogmática jurídicas contemporáneas y cubren todas las áreas del derecho" (Fabra. 2008, 4), ese carácter general que los caracterizó aun existe, pero ante la aparición de normas jurídicas con una textura abierta, muchas de ellas contenidas en el texto constitucional, su estudio ha adquirido mayor importancia. (Portela. 2009)

Ante el segundo punto, debe considerarse que las teorías descriptivas se caracterizan por brindar los elementos conceptuales requeridos para la comprensión mínima de las áreas de conocimiento y a partir de ellas es que se hace posible la formulación de un estado de cosas criticable, loable o merecedor de alguna reforma o cambio. En tal sentido, a pesar del uso cada más comprometido del lenguaje jurídico en la protección de determinados intereses, la mayoría de ellos identificable con los ideales constitucionales y los derechos humanos, la teoría positivista tiene las herramientas adecuadas para identificarlas y describirlos. Evaluar el mérito o desmérito del ordenamiento jurídico imperante o de las normas-utilizando la expresión de Austin- no corresponde al teórico positivista.

En síntesis, el positivismo jurídico sí es capaz de dar cuenta por los cambios ocurridos en la teoría

\footnotetext{
${ }^{16}$ Dicho dogma tienen su apogeo con la escuela de la exegesis francesa, pero puede rastrearse sus orígenes en la edad media con la recepción del derecho romano. (Carrillo. 2008, 262)

${ }^{17}$ Tal situación podría ser calificada de un hard case o caso difícil en las palabras de Dworkin.

${ }^{18}$ Se pueden caracterizar como normas generales que se extraen del sistema jurídico o de parte de él. Norberto Bobbio califica a este procedimiento como analogía iuris, para la distinguirlo de la analogía legis. Temas ampliamente desarrollados por los lógicos, en sus palabras. (Bobbio. 2007, pp. 238-246)
} 
jurídica en el Estado constitucional, en especial de los principios, no obstante, en la actualidad sea un lugar común el uso de un lenguaje menos neutral y más valorativo.

\section{REFERENCIAS BIBLIOGRÁFICAS}

ATIENZA, M., MANERO, J. (2007) “Dejemos atrás el positivismo jurídico”. En ISONOMIA. No. 27.

BOBBIO, N. (2007) “Teoría general del derecho”. 3a edición. Editorial Temis. Bogotá.

CARRILLO, Y. (2008) “Temas y problemas de la filosofía del derecho". Ediciones Doctrina y ley Ltda. Bogotá.

DWORKIN, R. (1989) "Los derechos en serio". Traduc. Maria Guastavino. Editorial Ariel. S.A. 2a edición. Barcelona.

FABRA, J. (2008) “El positivismo jurídico contemporáneo: esbozo de una defensa y de una conceptualización de sus tres tesis fundamentales". En: Saber, Ciencia y Libertad. Vol. 3, no. 1

"Principios, moral y positivismo jurídico: respuestas y redefinición del positivismo contemporáneo". (2008) En revista Jurídica Mario Alario D' filippo. Universidad de Cartagena. Rescatado en: https://www.unicartagena.edu.co/derechoycienciaspoliticas/revistajuridica/ejemplar1/nro_107_principios_moral_y_positivismo.pdf

GARCíA, A. (2003) "La teoría del derecho en tiempos del constitucionalismo". En Neoconstitucionalismo(s). Editorial Trotta. Madrid.

HART, H.L.A. (1963) “El concepto del derecho". Abeledo-perrot. Buenos Aires.

(1980) "El nuevo desafío al positivismo jurídico". En: Revista de ciencias sociales. No. 36

(2000) "Post scriptum al concepto del derecho". Traduc. y notas preliminares Rolando Tamayo y Salmoran. Universidad Nacional Autonoma de México.

HIMMA, K. (2011) "Derecho y Moral: el debate entre el positivismo jurídico inclúyete y el excluyente". Universidad Externado de Colombia. Bogotá.

NINO, C. (2003) "Introducción al análisis del derecho". 2ª edición ampliada y revisada. 12ạ reimpresión. Editorial Astrea. Buenos Aires.

PORTELA, J. (2009) "Los principios jurídicos y el neoconstitucionalismo". En Revista de Fundamentación Jurídica Dikaion. Núm. 18-33-54. Universidad de la Sabana.

JIMÉNEZ, R., FABRA, J., GUZMÁN, C. (2007-2008) "Riggs Contra Palmer". Tribunal de Apelaciones de Nueva York - 115 Ny 506. Traducción. Revista Telemática de Filosofía del Derecho, № 11. Disponible también online: http://www.rtfd.es/numero11/21-11.pdf 